\title{
The Inspiration of Hongqiao Traffic Hub to the Planning of Cruise Ship
}

\section{Home}

\author{
Wenbai LIU ${ }^{1, a}$,Qifei FANG ${ }^{1, b}$ and Zhouxiang WU ${ }^{1, c}$ \\ ${ }^{1}$ College of Ocean Science and Engineering,Shanghai Maritime University, 1550 Pudong \\ Avenue,Shanghai,201306,China \\ ${ }^{a}$ liuwb8848@163.com ${ }^{b}$ fangqifei05@163.com ${ }^{c}$ x371685880@sina.com
}

Keywords: Hongqiao transport hub, cruise ship home, planning

Abstract. The rapid development of the cruise industry, as a new type of vehicle is also a tourism product, its planning and operation and management of the existing system made a huge challenge, and Hongqiao transport hub planning in the country is at the forefront of the same Transportation hub.The same as the transport hub,we hope that the cruise ship home can learn from Hongqiao transport hub construction experience, in the land and sea or land and sea air transport planning a new breakthrough, co-ordination arrangements, the cruise port to maximize the potential.

\section{Introduction}

With the aging of China's population and the rise of the middle class in the country, coupled with the increasingly saturated market in the cruise industry in Europe and the United States, some industries have shifted to Asia. At present, the development of the cruise industry in China is still in its infancy, and the related facilities and services are still not mature. Few homeports of cruise ships are in a profitable state and face bottlenecks in the development process. This article hopes to use the current mature airport planning and operation management model as a reference to try to solve this development dilemma.

\section{Cruise Industry Development Status}

Modern cruise ships first appeared in the 1930s. Since then, they have developed rapidly. At present, the earliest and most developed areas of cruise industry in the world are North America and Europe. Supported by their relatively strong spending power, there are also many natural attractions. Scenery, so developed rapidly at the beginning of the industry. Taking the world's largest homeport of Miami cruises as an example, it received revenue of 8 billion U.S. dollars from the consumption of the cruise ship itself and tourists only in 2000, and also created 345,000 jobs. At present, there are more than 10 million passengers in cruises around the world. At the same time, Asia is the new growth point. Even during the financial crisis, it is still alive. However, with the slowdown in economic development in China, the economic growth brought by cruise ships has become the focus of attention of the central government and governments at all levels. In April 2015, the Ministry of Communications issued the "National Coastal Cruise Port Layout Plan" and proposed that before 2030, 2-3 trunk ports should be formed along the coast of the country, with the port of origin as the main port, and the port of visit as a supplementary port. The layout will 
form 12 departure ports, namely: Dalian Port, Tianjin Port, Qingdao Port, Yantai Port, Shanghai Port, Ningbo-Zhoushan Port, Xiamen Port, Shenzhen Port, Guangzhou Port, Sanya Port, Haikou Port and Beihai Port. It is estimated that by 2030, the passenger throughput of coastal ports will reach 30 million passengers.

\section{The Dilemma of Cruise home port development}

As a traditional continental country, combined with the influence of war, the development of China's waterway passenger transport industry has been able to develop since the founding of New China, and it has started much later than in foreign countries. At present, China's waterway passenger transport market is subject to historical factors and the time-consuming demands of rapid economic development. The development is relatively slow. There are few passengers who choose waterways. In 2015, the number of waterway passengers in China was only 260 million , which accounted for only $1.2 \%$ of the national passenger traffic in that year. Ports carry mostly bulk commodity freight services. The existing passenger ports are relatively small in scale and their facilities are also very simple. They are not sufficient to support the development needs of cruise ships.

Some regions are not fully aware of the importance of industrial upgrading and are still eating the old model of the previous economic development model. Tourism as a tertiary industry has less pollution and higher added value than traditional manufacturing industries. Talent and capital are more attractive. The clustering effect of the service industry can further stimulate the prosperity of other industries. At the same time, the shortage of talents in related fields is also a major problem. At present, there is no relevant professional personnel training at the Asia Cruise Academy, which is jointly organized by Shanghai Port Group and Shanghai Maritime University. Related industry development is also in its infancy.

Taking 2013 as an example, in the various revenue components of Shanghai Wusongkou International Cruise Port Development Co., Ltd. (see Fig. 1), the proportion of cruise ship berthing revenue to total revenue is approximately $55 \%$, and the revenue from ship supply business accounts for the total revenue. The income of Boat for business is about $18 \%$, and the proportion of ticket agency and advertising revenue to total revenue is about $7 \%$. From the figure, it is not difficult to find that the profit model of Wusongkou cruise home port is relatively single, and it lacks revenue from passenger consumption. Development is still in its infancy.

On the other hand, foreign cruise companies have long been in a monopoly state in this area, including the operation and management of an entire industrial chain. The construction of Miami's home port in the United States is even based on the needs of cruise companies, but Chinese independently operated cruise company are not exist. 


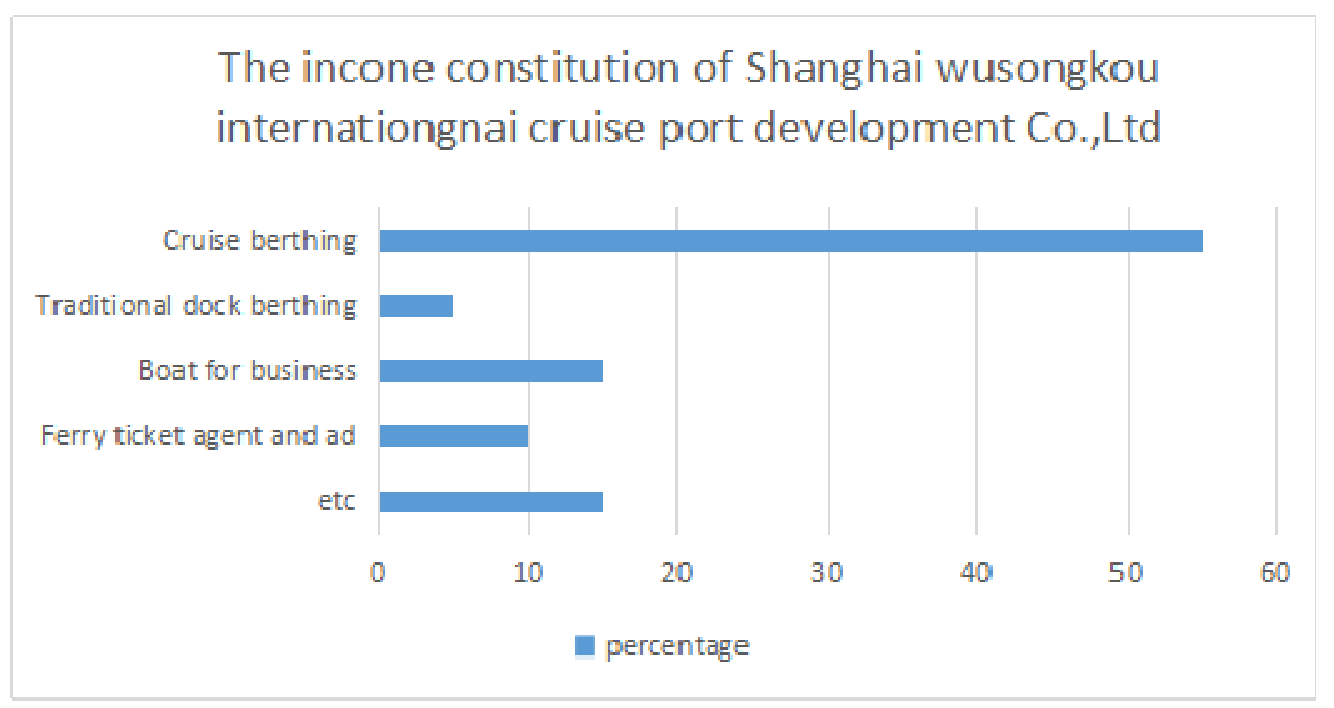

Fig.1

The Advantage of Hongqiao Transportation Hub

The Hongqiao Transportation Hub brings together a variety of modes of transportation, and at the same time, it is the core city in East China and is under tremendous pressure for the flow of people. At the beginning of the design, it upholds the design ideas of "priority in public transportation, separation of stations and stations", "separation of quick and slow, Intercommunication redundancy". Give full play to various modes of transportation, the dynamics of various transportation systems, make them into systems, facilitate operations, and unify platforms and operations. At present, the average daily traffic volume of the Hongqiao transportation hub is 910,000 person-times, with a peak of 1,240,000 person-times per day. Such person traffic is far from the design peak and is still within the acceptable range. This kind of design experience and planning layout concept is advanced in the country and even in the world.

After the completion of the Hongqiao Transportation Hub, it has brought into full play the consumerism brought about by the concentration of people. It has built commercial facilities such as retail stores, catering shops, hotels, office buildings, and billboards, and has released the commercial potential of transportation hubs. Drive the appreciation of surrounding land and realize the dynamic balance between input and output.

Hongqiao Transportation Hub has made many efforts and innovations in energy conservation, emission reduction and sustainable development. New breakthroughs have been made in comprehensive consideration of land use, water saving, energy saving and utilization of new energy, including the use of vertical Double U parallel ground source heat pump air-conditioning systems, solar hot water systems, and solar energy generation systems, which greatly reduces energy consumption and pollution of the environment.

The inspiration for Haikou New Harbor Planning

Haikou has a large number of "tidal populations" in certain seasons because of its special geographical location and abundant tourist resources. These people put pressure on Haikou's transport hubs when they enter and leave Haikou City. Facilities are insufficient to support the needs of development and a new traffic model is urgently needed to solve existing problems, and the Hongqiao model provides some relevant experience. Specifically speaking, it is necessary to 
make overall planning and layout, rationalize and integrate various modes of transportation, strengthen linkages between transportation systems, clarify the specificity of the cruise industry as a means of transport and tourism products, accurately position passengers, and build supporting facilities. On the premise of ensuring convenience, there will be less industrialization and more personalized services. The establishment of an aircraft-cruise-aircraft operating system, on the other hand, the inclusion of high-speed railways in the passenger transportation system can play a major role in this well-developed mode of transport in China.

Drawing on the development experience of the Hongqiao transportation hub, we will vigorously develop the core role of the home port of the cruise ship as a transportation hub, rationally divide the commercial and office areas, and draw on the overall planning and layout strategy of the "two axes plus one piece" of the Hongqiao hub (Fig.3).

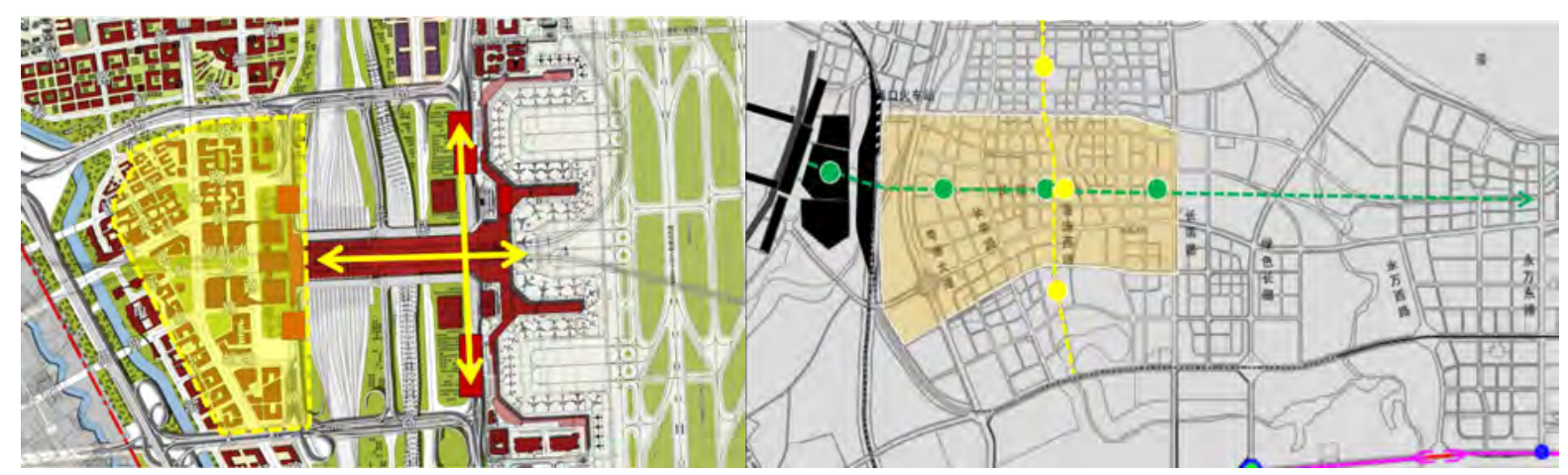

Fig2 Hongqiao Hub "Double Axis with One plat" Layout Planning(left)

Fig3 Conceptual layout of the New Seaport sea-iron hub(right)

Avoid exaggerated, blind construction, planning and construction should meet the actual needs, in the process of the construction of ports and related facilities, try to avoid damage to the existing system. The construction work should be completed in stages as much as possible. On the one hand, the scale of the project should be controlled to ensure the construction quality. On the other hand, the operating income should be used to make up for the lack of funds for follow-up development. At the same time, the PPP model or the mode of co-building the home port of cruise with the cruise company can be adopted to solve the problem of insufficient funds.

China currently lacks experience in the operation of cruise ports. However, the operating mode of domestic airports has been relatively mature. It is also a port area and its operating models have similarities. On the one hand, it will absorb the business model of airport-dominated transportation hubs and make differentiated service advantages. On the other hand, you can "get acquainted with" the famous overseas cruise port operators to learn advanced management techniques and experience.

\section{Conclusion}

With the convening of the Nineteenth Party Congress, we pointed out a new road for our related industries: Socialism with Chinese characteristics has entered a new era, and the main social contradictions in our country have also been transformed into people's ever-growing needs for a better life and inadequate balance. The contradiction between development. After the reform and 
opening up, China's economy has developed rapidly and the people's living standards have greatly improved. Nowadays, there are many problems brought about by extensive developments that need to be resolved. Even the traditional engineering industry needs to focus more on people's needs. Planning itself is for development, and further for human development. Adapting planning to the needs of the people is not only a new opportunity but also a new challenge.

\section{References:}

[1] Wang Xianglin. Devoting Major Efforts to Developing Shanghai Cruise Economy [J]. Legal System and Economy, 2010(1):112-113.

[2] Cai Erbing, Shi Jianyong. Shanghai Wushaokou International Cruise Port Business Model[J]. Ocean Transportation Management, 2014, 36(8):25-28.

[3]Wang Xiaochuan. Analysis and Reference of the Development of International Airport's Nearest Neighbor Region [J]. Urban Planning Journal, 2003(3):65-68.

[4] Liu Wujun. Comprehensive Transportation Hub Planning [M]. Shanghai Science and Technology Press, 2015. 